\title{
MEXAHИКА
}

\section{Bending of a Sandwich Beam by Local Loads in the Temperature Field}

\section{E. I. Starovoitov, D. V. Leonenko}

Eduard I. Starovoitov, https://orcid.org/0000-0002-2550-5377, Belarusian State University of Transport, 246653, Belarus, Gomel, Kirova Str., 34, edstar0@yandex.by

Denis V. Leonenko, https://orcid.org/0000-0001-8003-9279, Belarusian State University of Transport, 246653, Belarus, Gomel, Kirova Str., 34, leoden@tut.by

Deformation of sandwich beam in a temperature field under the action of uniformly distributed and sinusoidal local loads is considered. An analytical view of the loads was set by using functions of Heaviside. To describe kinematic properties of an asymmetric through thickness of sandwich beam we have accepted the hypotheses of a broken line as follows: Bernoulli's hypothesis is true in the thin bearing layers; Timoshenko's hypothesis is true in the compressible through thickness filler with a linear approximation of displacements through the layer thickness. The kinematic conditions of simply supported faces of the beam on the immovable in space rigid bases are presumed on the boundary. The filler's work is taken into account in the tangential direction. Temperature variations were calculated by the formula obtained from averaging thermophysical properties of the materials of the layers through the beam thickness. Stress and strain are related by relations of the deformation theory of plasticity. By the variational method a system of differential equilibrium equations has been derived. The solution of the boundary value problem of thermo-elastoplasticity is reduced to the search for four functions, namely: deflections and lengthwise displacements of the medial surfaces of the bearing layers. An analytical solution has been derived by the method of elastic solutions. In the case of repeated alternating loading solution using Moskvitin theorem received. Numerical analysis of solutions is performed for a continuous, locally distributed and repeated alternating loads. The graphs of stresses and displacements in sandwich beam under the isothermal and thermal-force loads are given.

Key words: local uniformly distributed and sinusoidal loads, sandwich elastic-plastic beam, compressible filler, temperature field.

DOI: 10.18500/1816-9791-2018-18-1-69-83
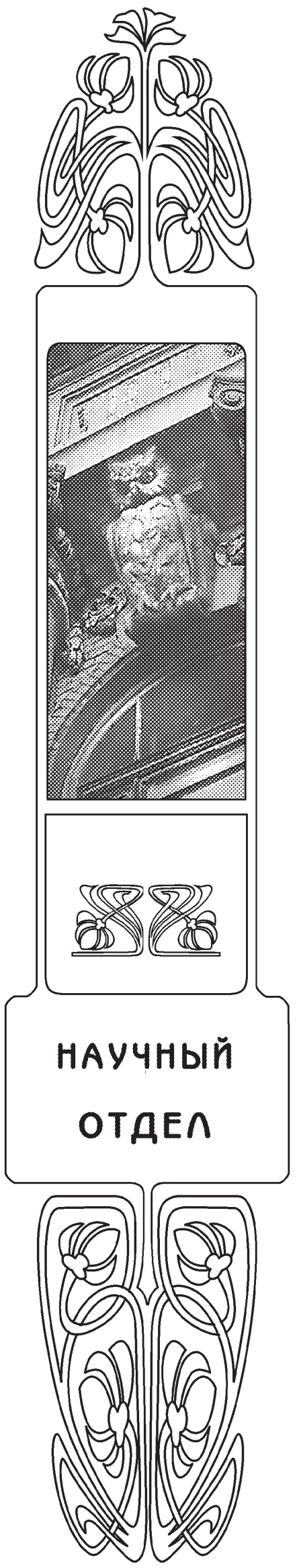


\section{INTRODUCTION}

In recent years, a considerable increase in the demand for the use of layered thinwalled structural elements in aircraft-, rocket-, machine-, instrument- and shipbuilding, mining and transportation of energy. This necessitates the development of mathematical models and methods of their calculation on various types of loads.

In monographs [1,2], various mathematical models of static and dynamic deformation of multilayered and three-layer structural elements are considered, statements of boundary-problems are given, and methods for their calculation are presented. The isothermal dynamic deformation of layered (three-layer) structural elements, including those connected to an elastic foundation, under the action of continuous and local loads are investigated in [3-11]. The statements and solution methods of boundary-value problems on isothermal deformations, including cyclic ones, of elastoplastic composite structural elements are presented in [12-19].

In the present work, the statement and an analytical solution of a boundary-value problem on the cyclic local thermal-force deformation of a three-layer elastoplastic beam of rectangular cross section with a compressible filler are given. The account of compressibility allows one to describe the deformation of three-layer beams at thermalforce loadings more adequately. From the mathematical point of view, this complicates the problem and increases the numbers of required functions and equilibrium equations. A numerical test of the solution obtained is performed in the case of a metal-polymer beam.

\section{STATEMENT OF THE BOUNDARY-VALUE PROBLEM}

Let us consider a three-layer beam asymmetric across its thickness (Fig. 1). For its isotropic load-carrying layers, the Bernoulli hypotheses are assumed. On contact borders, displacements are considered continuous. Materials of the load-carrying layers

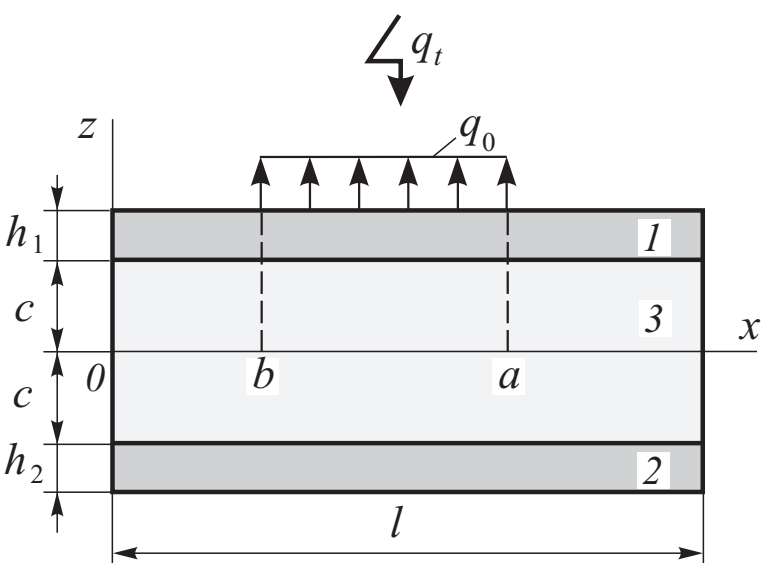

Fig. 1. Design diagram of a three-layer beam with a compressible filler: 1, 2 - load-carrying layers; $3-$ filler are incompressible in the thickness direction, compression of the filler is taken into account, and strains are small. A system of coordinates $x, y$, and $z$ is connected to the median plane of filler. A surface load $q(x)$ and a thermal flow of intensity $q_{t}$, directed perpendicularly to the load-carrying layer 1 operate on the beam. At its end faces, in the first and second load-carrying layers, forces $N_{p}^{(1)}, Q_{p}^{(1)}, M_{p}^{(1)}, N_{p}^{(2)}$, $Q_{p}^{(2)}$ and $M_{p}^{(2)}$ can be given; the subscript $p$ takes the values 0 and 1 , specifying the end face on which the forces are given; $w_{k}(x)$ and $u_{k}(x)$ are the deflections and longitudinal displacements of median surfaces of the load-carrying layers; $h_{k}$ is thickness of a $k$ th layer; $h_{3}=2 c(k=1,2,3$ is the layer number $) ; b_{0}$ is width of the beam.

The surface e $z=-c-h_{2}$ and contour of the beam are thermally insulated. The solution of the heat conduction equation is found by the method of averaging the 
thermophysical characteristics of materials across the thickness of the package of a plate. This allows one to calculate the nonuniform temperature field $T(z)$, measured from some reference temperature $T_{0}$, by the formula [2]:

$$
\begin{gathered}
T=\frac{q H}{\lambda}\left\{\tau+\frac{1}{2}\left(s+\frac{c+h_{2}}{H}\right)^{2}-\frac{1}{6}--\frac{2}{\pi^{2}} \sum_{n=1}^{\infty} \frac{(-1)^{n}}{n^{2}} \cos \left[\pi n\left(s+\frac{c+h_{2}}{H}\right)\right] e^{-n^{2} \pi^{2} \tau}\right\}, \\
\tau=\frac{a t}{H^{2}}, \quad a=\sum_{k=1}^{3} \lambda_{t k} h_{k} / \sum_{k=1}^{3} \rho_{k} C_{k} h_{k}, \quad H=\sum_{k=1}^{3} h_{k} .
\end{gathered}
$$

where $\lambda_{t k}, C_{k}$, and $\rho_{k}$ are the heat conductivity, heat capacity, and density of the material of a $k$ th layer, respectively.

The displacements $u(k)(x, z)$ and $w^{(k)}(x, z)$ of layers can be expressed in terms of four required functions $w_{1}(x), u_{1}(x), w_{2}(x)$, and $u_{2}(x)$ - deflections and longitudinal displacements of median surfaces of the load-carrying layers and filler:

- in the load-carrying layers

$$
\begin{aligned}
& u^{(1)}=u_{1}-\left(z-c-\frac{h_{1}}{2}\right) w_{1, x}, \quad w^{(1)}=w_{1}\left(c \leqslant z \leqslant c+h_{1}\right), \\
& u^{(2)}=u_{2}-\left(z+c+\frac{h_{2}}{2}\right) w_{2, x}, \quad w^{(2)}=w_{2}\left({ }^{u} c^{\cup} h_{2} \leqslant z \leqslant \cup c\right) ;
\end{aligned}
$$

- in the filler

$$
\begin{gathered}
u^{(3)}=\left(1+\frac{z}{c}\right)\left(\frac{1}{2} u_{1}+\frac{h_{1}}{4} w_{1, x}\right)+\left(1-\frac{z}{c}\right)\left(\frac{1}{2} u_{2}-\frac{h_{2}}{4} w_{2}, x\right), \\
w^{(3)}=\frac{1}{2}\left(1+\frac{z}{c}\right) w_{1}+\frac{1}{2}\left(1-\frac{z}{c}\right) w_{2}\left({ }^{u} c \leqslant z \leqslant c\right),
\end{gathered}
$$

where $z$ is the coordinate of the fiber considered, the comma in subscripts designates differentiation with respect to the coordinate following it.

Components of the stress tensor follow from (2) and Cauchy relations [2]. The internal forces in layers are expressed as

$$
\begin{gathered}
N_{x}^{(k)}=b_{0} \int_{h_{k}} \sigma_{x x}^{(k)} \mathrm{d} z, \quad M_{x}^{(k)}=b_{0} \int_{h_{k}} \sigma_{x x}^{(k)} z \mathrm{~d} z, \quad Q^{(3)}=b_{0} \int_{h_{3}} \sigma_{x z}^{(3)} \mathrm{d} z, \\
N_{z}^{(3)}=b_{0} \int_{h_{3}} \sigma_{z z}^{(3)} \mathrm{d} z, \quad M_{x z}^{(3)}=b_{0} \int_{h_{3}} \sigma_{x z}^{(3)} z \mathrm{~d} z,
\end{gathered}
$$

where $\sigma_{x x}^{(k)}, \sigma_{x z}^{(3)}$ and $\sigma_{z z}^{(3)}$ are components of the stress tensor.

Further, we accept the kinematic boundary conditions of simple support for end faces of the beam on spatially motion-less rigid supports. Then, in the cross sections $x=0, l$ ( $l$ is length of the beam), the following requirements have to be obeyed:

$$
w_{k}=u_{k}, x=w_{k}, x x=0 \quad(k=1,2) .
$$


In layers of the core, the following physical equations of state, corresponding to the Ilyushin theory of small elasto-plastic deformations, with account of temperature, a valid:

$$
\begin{gathered}
s_{i}^{(k)}=2 G_{k}\left(1-\omega_{k}\left(\varepsilon_{i}^{(k)}, T_{k}\right)\right) e_{i}^{(k)}, \quad s_{x z}^{(3)}=2 G_{3}\left(1-\omega_{3}\left(\varepsilon_{i}^{(3)}, T_{k}\right)\right) e_{x z}^{(3)}, \\
\sigma^{(k)}=3 K_{k}\left(\varepsilon^{(k)}-\alpha_{0 k} T_{k}\right) \quad(i=x, z ; \quad k=1,2,3)
\end{gathered}
$$

where $s_{i}^{(k)}, e_{i}^{(k)}$, and $\sigma^{(k)}, \varepsilon^{(k)}$ are the deviatoric and spherical parts of stress and strain tensors; $s_{x z}^{(3)}$ and $e_{x z}^{(3)}$ are the shear stresses and strains in the filler; $G_{k}\left(T_{k}\right)$ and $K_{k}\left(T_{k}\right)$ are temperature-dependent elastic moduli of the material of a $k$ th layer, calculated by the linear Bell formula [2]; $\omega^{(k)}\left(e_{i}^{(k)}, T_{k}\right)$ is a temperature-dependent nonlinearity (plasticity) function $[2] ; \varepsilon_{i}^{(k)}$ is the intensity of strains; $\alpha_{0 k}$ is the coefficient of linear thermal expansion; $T_{k}$ is temperature in a $k$ th layer.

The equilibrium equations in displacements for the beam considered are found by the Lagrange variational method. It will not be different from that given in [16]. The difference lies in the nonlinear member, which will contain thermal components instead of radiation.

To solve such boundary-value problems, approximate or numerical methods have to be used. Each of them have its own advantages and drawbacks. The approximate methods, such as the method of elastic solution, are convenient if the analytical solution of a corresponding problem of elastic theory are known and boundary conditions rather simple, for example, rigid fixation or hinged supporting. In other cases, more preferable are numerical methods.

In the case considered, the solution of the corresponding problem of the elasticity theory is known, therefore, we use the method of elastic solution, which allows one to present it in the following iterative form:

$$
\begin{aligned}
& a_{1} u_{1}^{n}-a_{1} u_{2}^{n}-a_{4} u_{1, x x}^{n}-a_{5} u_{2}^{n},_{x x}+a_{2} w_{1, x}^{n}+a_{3} w_{2}^{n},_{x}-2 a_{6} w_{1, x x x}^{n}+a_{7} w_{2}^{n}, x x x=p_{\omega}^{(n-1)}, \\
& -a_{1} u_{1}^{n}+a_{1} u_{2}^{n}-a_{5} u_{1}^{n}{ }_{x x}-a_{9} u_{2}^{n},_{x x}-a_{10} w_{1, x}^{n}-a_{17} w_{2}^{n},_{x}-a_{6} w_{1}^{n},_{x x x}+2 a_{7} w_{2}^{n}{ }_{x x x}=h_{\omega}^{(n-1)}, \\
& -a_{2} u_{1, x}^{n}+a_{10} u_{2}^{n},_{x}+2 a_{6} u_{1, x x x}^{n}+a_{6} u_{2}^{n}, x x x+a_{11} w_{1, x x}^{n}-a_{12} w_{2}^{n},_{x x}+ \\
& +a_{15} w_{1, x x x x}^{n}-a_{16} w_{2}^{n},{ }_{x x x x}+a_{8} w_{1}^{n}-a_{8} w_{2}^{n}=q+q_{\omega}^{(n-1)}, \\
& -a_{3} u_{1, x}^{n}+a_{17} u_{2}^{n},_{x}-a_{7} u_{1, x x x}^{n}-2 a_{7} u_{2}^{n},_{x x x}-a_{12} w_{1, x x}^{n}+a_{14} w_{2}^{n},_{x x}- \\
& -a_{16} w_{1}^{n}{ }_{x x x x}+a_{13} w_{2}^{n}, x x x x-a_{8} w_{1}^{n}+a_{8} w_{2}^{n}=g_{\omega}^{(n-1)} .
\end{aligned}
$$

where $n$ is the number of linear approximation. The temperature terms $q_{t}$ and coefficients $a_{1},, a_{17}$ are determined considering the temperature dependence of the elastic parameters of materials across the package thickness:

$$
\begin{gathered}
q_{t}=-\frac{H_{2}^{t}}{b_{0}}=-\frac{N_{z}^{(3) t}}{2 c b_{0}}, \quad a_{1}=\frac{\mathrm{L}_{0}\left(G_{3}\right)}{4 c^{2}}, \\
a_{2}=\left(1+\frac{h_{1}}{2 c}\right) \frac{\mathrm{L}_{0}\left(G_{3}\right)}{4 c}+\frac{\mathrm{L}_{1}\left(G_{3}\right)}{4 c^{2}}-\frac{\mathrm{L}_{0}\left(K_{3}^{-}\right)}{4 c}-\frac{\mathrm{L}_{1}\left(K_{3}^{-}\right)}{4 c^{2}}, \\
a_{3}=\left(1+\frac{h_{1}}{2 c}\right) \frac{\mathrm{L}_{0}\left(G_{3}\right)}{4 c}-\frac{\mathrm{L}_{1}\left(G_{3}\right)}{4 c^{2}}+\frac{\mathrm{L}_{0}\left(K_{3}^{-}\right)}{4 c}+\frac{\mathrm{L}_{1}\left(K_{3}^{-}\right)}{4 c^{2}},
\end{gathered}
$$




$$
\begin{aligned}
& a_{4}=\mathrm{L}_{0}\left(K_{1}^{+}\right)+\frac{\mathrm{L}_{1}\left(K_{3}^{+}\right)}{2 c}+\frac{\mathrm{L}_{0}\left(K_{3}^{+}\right)}{4}+\frac{\mathrm{L}_{2}\left(K_{3}^{+}\right)}{4 c^{2}}, \quad a_{5}=\frac{\mathrm{L}_{0}\left(K_{3}^{+}\right)}{4}-\frac{\mathrm{L}_{2}\left(K_{3}^{+}\right)}{4 c^{2}}, \\
& a_{6}=\frac{L_{1}\left(K_{1}^{+}\right)}{2}-\frac{L_{0}\left(K_{1}^{+}\right)}{2}\left(c+\frac{h_{1}}{2}\right)+\frac{h_{1} L_{1}\left(K_{3}^{+}\right)}{8 c}+\frac{h_{1} L_{0}\left(K_{3}^{+}\right)}{16}+\frac{h_{1} L_{2}\left(K_{3}^{+}\right)}{16 c^{2}}, \\
& a_{7}=\frac{h_{2}}{8 c^{2}}\left(c^{2} \mathrm{~L}_{0}\left(K_{3}^{+}\right)-\mathrm{L}_{2}\left(K_{3}^{+}\right)\right), \quad a_{8}=\frac{\mathrm{L}_{0}\left(K_{3}^{+}\right)}{4 c^{2}}, \\
& a_{9}=\mathrm{L}_{0}\left(K_{2}^{+}\right)-\frac{\mathrm{L}_{1}\left(K_{3}^{+}\right)}{2 c}+\frac{\mathrm{L}_{0}\left(K_{3}^{+}\right)}{4}+\frac{\mathrm{L}_{2}\left(K_{3}^{+}\right)}{4 c^{2}}, \\
& a_{10}=\left(1+\frac{h_{1}}{2 c}\right) \frac{\mathrm{L}_{0}\left(G_{3}\right)}{4 c}+\frac{\mathrm{L}_{1}\left(G_{3}\right)}{4 c^{2}}+\frac{\mathrm{L}_{0}\left(K_{3}^{-}\right)}{4 c}-\frac{\mathrm{L}_{1}\left(K_{3}^{-}\right)}{4 c^{2}}, \\
& a_{11}=\frac{h_{1} \mathrm{~L}_{0}\left(K_{3}^{-}\right)}{4 c}+\frac{h_{1} \mathrm{~L}_{1}\left(K_{3}^{-}\right)}{4 c^{2}}-\left(1+\frac{h_{1}}{2 c}\right)^{2} \frac{\mathrm{L}_{0}\left(G_{3}\right)}{4}-\left(1+\frac{h_{1}}{2 c}\right) \frac{\mathrm{L}_{1}\left(G_{3}\right)}{2 c}-\frac{\mathrm{L}_{2}\left(G_{3}\right)}{4 c^{2}} \text {, } \\
& a_{12}=\left(1+\frac{h_{1}}{2 c}\right)\left(1+\frac{h_{2}}{2 c}\right) \frac{\mathrm{L}_{0}\left(G_{3}\right)}{4}-\frac{\mathrm{L}_{2}\left(G_{3}\right)}{4 c^{2}}+\frac{\mathrm{L}_{1}\left(K_{3}^{-}\right)}{8 c^{2}}\left(h_{1}-h_{2}\right)+ \\
& +\frac{\mathrm{L}_{0}\left(K_{3}^{-}\right)}{8 c}\left(h_{1}+h_{2}\right)-\frac{\mathrm{L}_{1}\left(G_{3}\right)}{8 c^{2}}\left(h_{1}-h_{2}\right) \text {, } \\
& a_{13}=\mathrm{L}_{2}\left(K_{2}^{+}\right)+\mathrm{L}_{1}\left(K_{2}^{+}\right)\left(c+\frac{h_{2}}{2}\right)-\frac{h_{2}^{2} \mathrm{~L}_{1}\left(K_{3}^{+}\right)}{8 c}+\frac{h_{2}^{2} \mathrm{~L}_{0}\left(K_{3}^{+}\right)}{16}+\frac{h_{2}^{2} \mathrm{~L}_{2}\left(K_{3}^{+}\right)}{16 c^{2}}, \\
& a_{14}=\frac{h_{2} \mathrm{~L}_{0}\left(K_{3}^{-}\right)}{4 c}-\frac{h_{2} \mathrm{~L}_{1}\left(K_{3}^{-}\right)}{4 c^{2}}-\left(1+\frac{h_{2}}{2 c}\right)^{2} \frac{\mathrm{L}_{0}\left(G_{3}\right)}{4}+\left(1+\frac{h_{2}}{2 c}\right) \frac{\mathrm{L}_{1}\left(G_{3}\right)}{2 c}-\frac{\mathrm{L}_{2}\left(G_{3}\right)}{4 c^{2}} \text {, } \\
& a_{15}=\mathrm{L}_{2}\left(K_{1}^{+}\right)-\mathrm{L}_{1}\left(K_{1}^{+}\right)\left(c+\frac{h_{1}}{2}\right)+\frac{h_{1}^{2} \mathrm{~L}_{1}\left(K_{3}^{+}\right)}{8 c}+\frac{h_{1}^{2} \mathrm{~L}_{0}\left(K_{3}^{+}\right)}{16}+\frac{h_{1}^{2} \mathrm{~L}_{2}\left(K_{3}^{+}\right)}{16 c^{2}}, \\
& a_{16}=\frac{h_{1} h_{2}}{16 c^{2}}\left(c^{2} \mathrm{~L}_{0}\left(K_{3}^{+}\right)-\mathrm{L}_{2}\left(K_{3}^{+}\right)\right) \text {, } \\
& a_{17}=\left(1+\frac{h_{1}}{2 c}\right) \frac{\mathrm{L}_{0}\left(G_{3}\right)}{4 c}-\frac{\mathrm{L}_{1}\left(G_{3}\right)}{4 c^{2}}-\frac{\mathrm{L}_{0}\left(K_{3}^{-}\right)}{4 c}+\frac{\mathrm{L}_{1}\left(K_{3}^{-}\right)}{4 c^{2}}, \\
& \mathrm{~L}_{n}\left(f_{k}(z)\right) \equiv \int_{h_{k}} f_{k}(z) z^{n} \mathrm{~d} z \quad(n=0,1,2), \quad K_{k}^{+}=K_{k}+\frac{4}{3} G_{k}, \quad K_{k}^{-}=K_{k}-\frac{2}{3} G_{k} .
\end{aligned}
$$

At the first step of approximation, the nonlinear terms in the additional loads $p_{\omega}^{(n-1)}$, $h_{\omega}^{(n-1)}, q_{\omega}^{(n-1)}$ and $g_{\omega}^{(n-1)}$ assumed equal to zero $\left(\omega_{k}^{(1)}=0\right)$ and further are calculated from results of the previous iteration:

$$
\begin{gathered}
p_{\omega}^{(n-1)}=\frac{1}{b_{0}}\left(H_{1}^{\omega(n-1)}-P_{1}^{\omega(n-1)}{ }_{x}\right), \quad h_{\omega}^{n-1}=\frac{1}{b_{0}}\left(H_{1}^{\omega(n-1)}+P_{2}^{\omega(n-1)}{ }_{x}\right), \\
q_{\omega}^{(n-1)}=\frac{1}{b_{0}}\left(S_{1}^{\omega(n-1)},_{x x}+H_{2}^{\omega(n-1)}-T_{1}^{\omega(n-1)}{ }_{x}\right), \\
g_{\omega}^{(n-1)}=\frac{1}{b_{0}}\left(S_{2}^{\omega(n-1)}{ }_{x x}-H_{2}^{\omega(n-1)}-T_{2}^{\omega(n-1)}{ }_{x}\right),
\end{gathered}
$$


where, nonlinear and thermal components of the internal forces in layers [3]

$$
\begin{aligned}
& H_{1}^{\omega(n-1)}=\frac{Q^{(3) \omega(n-1)}}{2 c}, \quad T_{1}^{\omega}=\left(1+\frac{h_{1}}{2 c}\right) \frac{Q^{(3) \omega(n-1)}}{2}+\frac{M_{x z}^{(3) \omega(n-1)}}{2 c}, \\
& H_{2}^{\omega(n-1)}=\frac{N_{z}^{(3) \omega(n-1)}}{2 c}, \quad T_{2}^{\omega(n-1)}=\left(1+\frac{h_{2}}{2 c}\right) \frac{Q^{(3) \omega(n-1)}}{2}-\frac{M_{x z}^{(3) \omega(n-1)}}{2 c}, \\
& S_{1}^{\omega(n-1)}=\left(c+\frac{h_{1}}{2}\right) N_{x}^{(1) \omega(n-1)}-M_{x}^{(1) \omega(n-1)}+\frac{h_{1}}{4} N_{x}^{(3) \omega(n-1)}+\frac{h_{1}}{4 c} M_{x}^{(3) \omega(n-1)}, \\
& S_{2}^{\omega(n-1)}=-\left(c+\frac{h_{2}}{2}\right) N_{x}^{(2) \omega(n-1)}-M_{x}^{(2) \omega(n-1)}-\frac{h_{2}}{4} N_{x}^{(3) \omega(n-1)}+\frac{h_{2}}{4 c} M_{x}^{(3) \omega(n-1)}, \\
& P_{1}^{\omega}=\frac{N_{x}^{(3) \omega(n-1)}}{2}+\frac{M_{x}^{(3) \omega(n-1)}}{2 c}+N_{x}^{(1) \omega(n-1)}, \\
& P_{2}^{\omega(n-1)}=\frac{N_{x}^{(3) \omega(n-1)}}{2}-\frac{M_{x}^{(3) \omega(n-1)}}{2 c}+N_{x}^{(2) \omega(n-1)}, \\
& N_{x}^{(k) \omega(n-1)}=\frac{4}{3} b_{0} G_{k} \int_{h_{k}}\left[\varepsilon_{x}^{(k)} \omega_{k}\right]^{(n-1)} \mathrm{d} z+3 b_{0} K_{k} \alpha_{0 k} \int_{h_{k}} T_{k} \mathrm{~d} z, \\
& M_{x}^{(k) \omega(n-1)}=\frac{4}{3} b_{0} G_{k} \int_{h_{k}}\left[\varepsilon_{x}^{(k)} \omega_{k} z\right]^{(n-1)} \mathrm{d} z+3 b_{0} K_{k} \alpha_{0 k} \int_{h_{k}} T_{k} z \mathrm{~d} z, \\
& N_{x}^{(3) \omega(n-1)}=\frac{2}{3} b_{0} G_{3} \int_{h_{3}}\left[\left(2 \varepsilon_{x}^{(3)}-\varepsilon_{z}^{(3)}\right) \omega_{3}\right]^{(n-1)} \mathrm{d} z+3 b_{0} K_{3} \alpha_{03} \int_{h_{3}} T_{3} \mathrm{~d} z, \\
& N_{z}^{(3) \omega(n-1)}=\frac{2}{3} b_{0} G_{3} \int_{h_{3}}\left[\left(2 \varepsilon_{z}^{(3)}-\varepsilon_{x}^{(3)}\right) \omega_{3}\right]^{(n-1)} \mathrm{d} z+3 b_{0} K_{3} \alpha_{03} \int_{h_{3}} T_{3} \mathrm{~d} z, \\
& M_{x}^{(3) \omega(n-1)}=\frac{2}{3} b_{0} G_{3} \int_{h_{3}}\left[\left(2 \varepsilon_{x}^{(3)}-\varepsilon_{z}^{(3)}\right) \omega_{3}\right]^{(n-1)} z \mathrm{~d} z+3 b_{0} K_{3} \alpha_{03} \int_{h_{3}} T_{3} z \mathrm{~d} z, \\
& Q^{(3) \omega(n-1)}=2 b_{0} G_{3} \int_{h_{3}}\left[\varepsilon_{x z}^{(3)} \omega_{3}\right]^{(n-1)} \mathrm{d} z, \quad M_{x z}^{(3) \omega(n-1)}=2 b_{0} G_{3} \int_{h_{3}}\left[\varepsilon_{x z}^{(3)} \omega_{3}\right]^{(n-1)} z \mathrm{~d} z \quad(k=1,2) .
\end{aligned}
$$

Then, boundary conditions (4) become

$$
w_{k}^{n}=u_{k}^{n}, x=w_{k}^{n}, x x=0 .
$$

Application of the method of thermo-elastic formulated allows on, at each step of approximation, to reduce the nonlinear boundary-value problem on thermoplastic bending of the beam to the corresponding linear (6) with additional loads (7). As a first approximation, we will take an analytical or numerical solution of the thermo-elasticity problem for the beam considered. 


\section{ANALYTICAL SOLUTION}

The solution of the system of differential equations (6) is sought in the form of trigonometric series, satisfying boundary conditions (8) automatically:

$$
\begin{array}{ll}
u_{1}^{n}=\sum_{m=1}^{\infty} U_{1 m}^{n} \cos \left(\frac{\pi m x}{l}\right), & u_{2}^{n}=\sum_{m=1}^{\infty} U_{2 m}^{n} \cos \left(\frac{\pi m x}{l}\right), \\
w_{1}^{n}=\sum_{m=1}^{\infty} W_{1 m}^{n} \sin \left(\frac{\pi m x}{l}\right), & w_{2}^{n}=\sum_{m=1}^{\infty} W_{2 m}^{n} \sin \left(\frac{\pi m x}{l}\right),
\end{array}
$$

where $U_{1 m}^{n}, U_{2 m}^{n}, W_{1 m}^{n}, W_{2 m}^{n}$ are the displacement amplitudes required.

The transverse load and additional forces in layers of the beam are also presented in the form of trigonometric series:

$$
\begin{array}{cl}
q=\sum_{m=1}^{\infty} q_{m} \sin \left(\frac{\pi m x}{l}\right), & q_{m}=\frac{2}{l} \int_{0}^{l} q(x) \sin \left(\frac{\pi m x}{l}\right) \mathrm{d} x, \\
q_{\omega}^{n-1}=\sum_{m=1}^{\infty} q_{\omega m}^{n-1} \sin \left(\frac{\pi m x}{l}\right), & q_{\omega m}^{n-1}=\frac{2}{l} \int_{0}^{l} q_{\omega}^{n-1}(x) \sin \left(\frac{\pi m x}{l}\right) \mathrm{d} x, \\
g_{\omega}^{n-1}=\sum_{m=1}^{\infty} g_{\omega m}^{n-1} \sin \left(\frac{\pi m x}{l}\right), & g_{\omega m}^{n-1}=\frac{2}{l} \int_{0}^{l} g_{\omega}^{n-1}(x) \sin \left(\frac{\pi m x}{l}\right) \mathrm{d} x, \\
h_{\omega}^{n-1}=\sum_{m=1}^{\infty} h_{\omega m}^{n-1} \cos \left(\frac{\pi m x}{l}\right), & h_{\omega m}^{n-1}=\frac{2}{l} \int_{0}^{l} h_{\omega}^{n-1}(x) \cos \left(\frac{\pi m x}{l}\right) \mathrm{d} x, \\
p_{\omega}^{n-1}=\sum_{m=1}^{\infty} p_{\omega m}^{n-1} \cos \left(\frac{\pi m x}{l}\right), & p_{\omega m}^{n-1}=\frac{2}{l} \int_{0}^{l} p_{\omega}^{n-1}(x) \cos \left(\frac{\pi m x}{l}\right) \mathrm{d} x .
\end{array}
$$

Inserting displacements (9), additional forces (10) into equilibrium equation (6), we arrive at a system of linear algebraic equations for determining the displacement amplitudes $U_{1 m}^{n}, U_{2 m}^{n}, W_{1 m}^{n}$ and $W_{2 m}^{n}$ required:

$$
\left\{\begin{array}{l}
b_{1} U_{1 m}^{n}+b_{2} U_{2 m}^{n}+b_{3} W_{1 m}^{n}+b_{4} W_{2 m}^{n}=p_{\omega m}^{n-1}, \\
b_{2} U_{1 m}^{n}+b_{5} U_{2 m}^{n}+b_{6} W_{1 m}^{n}-b_{7} W_{2 m}^{n}=h_{\omega m}^{n-1}, \\
b_{3} U_{1 m}^{n}+b_{6} U_{2 m}^{n}+b_{8} W_{1 m}^{n}+b_{9} W_{2 m}^{n}=q_{m}+q_{\omega m}^{n-1}, \\
b_{4} U_{1 m}^{n}-b_{7} U_{2 m}^{n}+b_{9} W_{1 m}^{n}+b_{10} W_{2 m}^{n}=g_{\omega m}^{n-1},
\end{array}\right.
$$

where the coefficients $b_{i}$ depend on the parameter $m$ and temperature through the coefficients $a_{n}$, which are determined in (6):

$$
\begin{gathered}
b_{1}=a_{1}+a_{4}\left(\frac{\pi m}{l}\right)^{2}, \quad b_{2}=-a_{1}+a_{5}\left(\frac{\pi m}{l}\right)^{2}, \quad b_{3}=a_{2} \frac{\pi m}{l}+2 a_{6}\left(\frac{\pi m}{l}\right)^{3}, \\
b_{4}=a_{3} \frac{\pi m}{l}-a_{7}\left(\frac{\pi m}{l}\right)^{3}, \quad b_{5}=a_{1}+a_{9}\left(\frac{\pi m}{l}\right)^{2}, \quad b_{6}=-a_{10} \frac{\pi m}{l}+a_{6}\left(\frac{\pi m}{l}\right)^{3},
\end{gathered}
$$




$$
\begin{gathered}
b_{7}=a_{17} \frac{\pi m}{l}+2 a_{7}\left(\frac{\pi m}{l}\right)^{3}, \quad b_{8}=-a_{11}\left(\frac{\pi m}{l}\right)^{2}+a_{15}\left(\frac{\pi m}{l}\right)^{4}+a_{8}, \\
b_{9}=a_{12}\left(\frac{\pi m}{l}\right)^{2}-a_{16}\left(\frac{\pi m}{l}\right)^{4}-a_{8}, \quad b_{10}=-a_{14}\left(\frac{\pi m}{l}\right)^{2}+a_{13}\left(\frac{\pi m}{l}\right)^{4}+a_{8} .
\end{gathered}
$$

The solution of system (11) can be presented in determinants or solved numerically. Then, using formulas (9), the required functions are calculated. Displacements in the load-carrying layers and filler follow from relations (2), strains - from Cauchy relations, and stresses - from (5).

\section{BEAM IN THE TEMPERATURE FIELD (SINGLE LOADING)}

Let the beam be subjected to a transverse load $q(x)=q_{0}=$ const. The coefficients of its expansion in series are

$$
q_{m}=\frac{2 q_{0}}{\pi m}(1-\cos (\pi m)) .
$$

If the surface load is distributed uniformly on an interval $a \leqslant x \leqslant b$ (rectangular load), as on the Fig. 1, then its analytical form and expansion coefficients are

$$
q(x)=q_{0}\left(H_{0}(b-x)-H_{0}(a-x)\right), \quad q_{m}=-\frac{2 q_{0}}{\pi m}\left(\cos \frac{\pi m b}{l}-\cos \frac{\pi m a}{l}\right),
$$

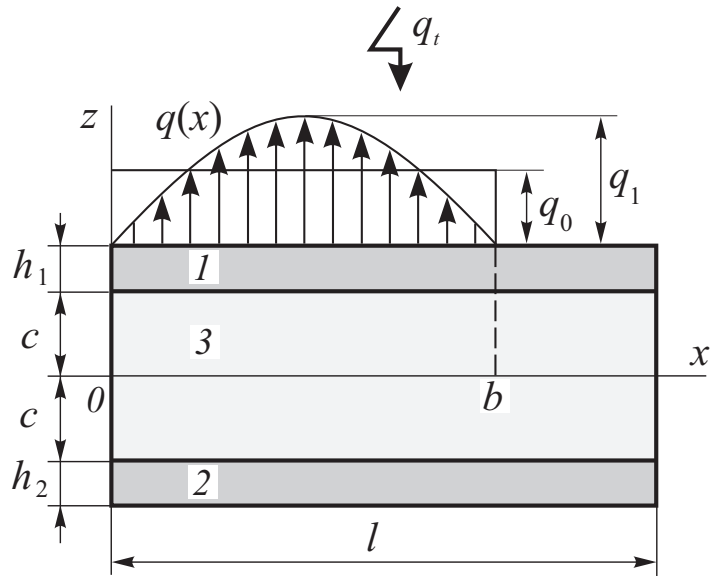

Fig. 2. Design diagram of a three-layer beam with a local sinusoidal loads where $H_{0}(x)$ is the Heaviside function and $q_{0}$ is loading intensity.

Suppose that on the surface consider the beam acts locally distributed in the region $0 \leqslant x \leqslant b$ a sinusoidal load $q(x)$ (Fig. 2):

$$
q(x)=q_{0} H_{0}(b-x) \sin \left(\frac{\pi x}{b}\right) .
$$

Substituting the load (14) to the corresponding formula from (10), we obtain expressions for the coefficients $q_{m}:$

$$
q_{m}=\frac{b q_{0}}{\pi}\left[\frac{1}{b m-l} \sin \frac{\pi(b m-l)}{l}-\frac{1}{b m+l} \sin \frac{\pi(b m+l)}{l}\right] \quad(m=1,2,3, \ldots) .
$$

Here should return $b m \neq l$, in order to avoid division by zero. If $m=p$, then

$$
q_{p}=\frac{2 q_{0}}{l} \int_{0}^{l} H_{0}(b-x)\left(\sin \frac{\pi p x}{l}\right)^{2} d x=\frac{q_{0}}{l} \int_{0}^{b}\left(1-\cos \frac{2 \pi p x}{l}\right) d x=\frac{q_{0} b}{l} .
$$

Determine the amplitude of the sinusoidal load, whose resultant is statically equivalent rectangular load acting on the same surface of the web. From the condition 
of equality of the areas occupied by these loads will receive:

$$
q_{0}^{\prime}=q_{0} l / \int_{0}^{l} \sin \left(\frac{\pi x}{l}\right) d x=\frac{1}{2} \pi q_{0} .
$$

Numerical results. The numerical realization of solution (6), (12)-(3). was carried out for a three-layer D16T-fluoroplastic-D16T beam, whose mechanical and thermo-plastical parameters are described in [2]. The relative thicknesses (to the length of beam) were assumed to be $h_{1}=0.04, h_{2}=0.02$ and $h_{3}=0.18$. The heat spent on heating the external metal layer was neglected owing to its thinness and small thermal capacity. Temperatures of the load carrying layers were assumed equal to that of the filler in the locations of their bonding: $T_{1}=T_{3}(c, t), T_{2}=T_{3}\left({ }^{u} c, t\right)$. The temperature field in the filler was calculated by formula (1), at $h_{1}=0, q_{t}=5000 \mathrm{~J} /\left(\mathrm{m}^{2} \cdot \mathrm{s}\right)$ at the instant of time $t=60 \mathrm{~min}$. The rated temperature on beam surface was $540 \mathrm{~K}$. The intensity of load $q_{0}={ }^{\lrcorner} 5 \mathrm{MPa}$. A function of plasticity was adopted in the form proposed in [16].

In Fig. 3 shows the change in deflections (a) and longitudinal displacements $(b)$ in the first layer along the axis of an elastic beam under the action of the statically equivalent distributed loads $(b=1): 1$ - rectangular; 2 - sinusoidal (both isothermal); 3 - sinusoidal temperature and force. Here, the maximum move more from a sinusoidal load. The difference between the curves under isothermal loading is $22 \%$. Thermal effects adds another $15 \%$ to the deflection of the sinusoidal load.

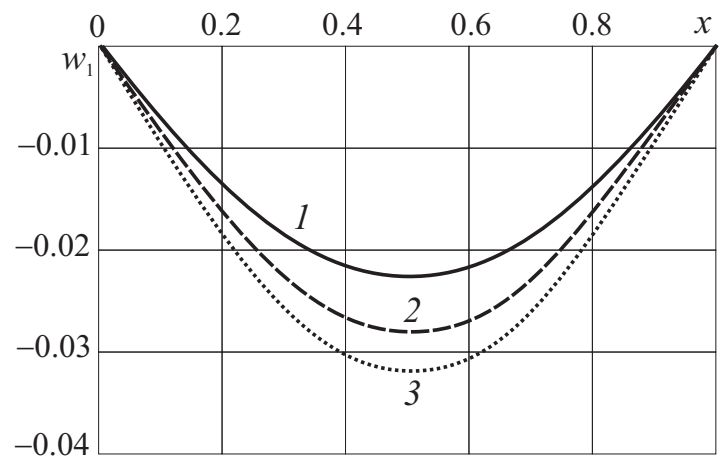

a

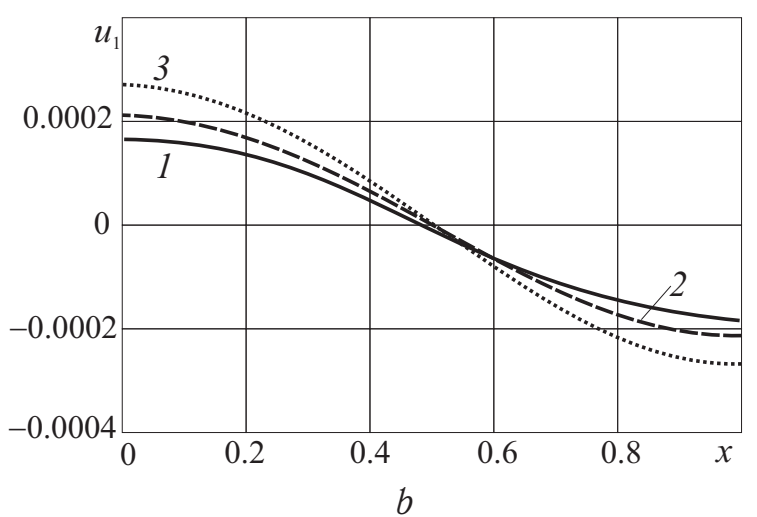

Fig. 3. Deflection $w_{1}(a)$ and longitudinal displacements $u_{1}(b)$ in the first layer along the axis of the statically equivalent distributed loads: 1 - rectangular; 2 - sinusoidal (both isothermal); 3 - sinusoidal temperature and force

\section{SIGN-VARIABLE LOADING IN A TEMPERATURE FIELD}

At a moment $t=t_{1}$, the beam is instantly unloaded and repeatedly loaded by forces $p^{\prime \prime}$ and $q^{\prime \prime}$, of opposite sign, varying with the same law as in the loading from its natural state. These forces create the fields of displacements $u_{1}^{\prime \prime}(x), w_{1}^{\prime \prime}(x), u_{2}^{\prime \prime}(x)$, and $w_{2}^{\prime \prime}(x)$, strain $\varepsilon_{x}^{\prime \prime(k)}(x, z), \varepsilon_{z}^{\prime \prime(3)}(x, z)$, and $\varepsilon^{\prime \prime \prime}{ }_{x z}^{(3)}(x, z)$, and stresses $\sigma_{x}^{\prime \prime(k)}(x, z), \sigma_{z}^{\prime \prime}(x)(x, z)$, and $\sigma_{x z}^{\prime \prime(3)}(x, z)$ in $k$ th layer of the beam.

We assume that, during the unloading and subsequent variable loading, temperature of the body remains constant and coincides with the temperature at the moment of beginning of unloading at all its points, i.e., $T^{\prime}(z)=T\left(z, t_{1}\right)$. The elastic moduli of layers materials are $G_{k}(z) \equiv G_{k}\left(T^{\prime}(z)\right)$, and $K_{k}(z) \equiv K_{k}\left(T^{\prime}(z)\right)$, and the corresponding loading trajectories fall into the class of simple ones according to Ilyushin [20]. 
For all the stress-strain states and loads considered, we introduce the following differences, in which the stresses, strains, displacements, and forces with one prime refer to the state before unloading, but those with two primes - to the second loading halfcycle:

$$
\begin{gathered}
\sigma_{x}^{(k) *}=\sigma_{x}^{\prime(k)}-{\sigma_{x}^{\prime \prime}}_{x}^{(k)}, \quad \sigma_{z}^{(3) *}=\sigma_{z}^{\prime(3)}-{\sigma_{z}^{\prime \prime}}_{z}^{(3)}, \quad \sigma_{x z}^{(3) *}=\sigma_{x z}^{\prime(3)}-\sigma_{x z}^{\prime \prime(3)}, \quad \varepsilon_{x}^{(k) *}=\varepsilon_{x}^{\prime(k)}-\varepsilon_{x}^{\prime \prime(k)}, \\
\varepsilon_{z}^{(3) *}=\varepsilon_{z}^{\prime(3)}-\varepsilon_{z}^{\prime \prime(3)}, \quad \varepsilon_{x z}^{(3) *}=\varepsilon_{x z}^{\prime(3)}-\varepsilon_{x z}^{\prime \prime(3)}, \quad u_{1}^{*}=u_{1}^{\prime}-u_{1}^{\prime \prime}, \quad w_{1}^{*}=w_{1}^{\prime}-w_{1}^{\prime}, \\
u_{2}^{*}=u_{2}^{\prime}-u_{2}^{\prime \prime}, \quad w_{2}^{*}=w_{2}^{\prime}-w_{2}^{\prime}, \quad q^{*}=q^{\prime}-q^{\prime \prime} \quad(k=1,2,3) .
\end{gathered}
$$

For the stresses and strains in (15) marked by an asterisk, we assume the following physical equations of state (5):

$$
\begin{gathered}
s_{i}^{(k) *}=2 G_{k}\left(1-\omega^{(k) *}\left(\varepsilon_{u}^{(k) *}, T_{k}\right)\right) e_{i}^{(k) *}, \quad s_{x z}^{(3) *}=2 G_{3}\left(1-\omega^{(k) *}\left(\varepsilon_{u}^{(k) *}, T_{k}\right)\right) e_{x z}^{(3) *}, \\
\sigma^{(k) *}=3 K_{k}\left(\varepsilon^{(k)}-\alpha_{0 k} T_{k}\right) \quad(i=x, z ; \quad k=1,2,3) .
\end{gathered}
$$

According to the Moskvitin theory [21], the universal nonlinearity functions $\omega^{(k)}$ in the load-carrying layers (16) are expressed in terms of plasticity function loading from the natural state:

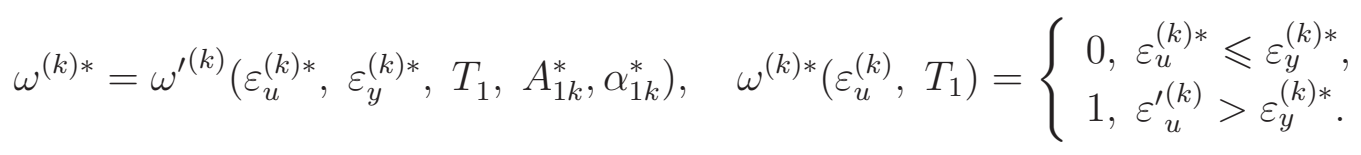

The physical nonlinearity of filler at the second loading half-cycle, in view of absence of residual strains from it, is still described by relations (7). As a result, we have

$$
\begin{aligned}
& \sigma_{\alpha \beta}^{(3) *}=2{\sigma^{\prime}}_{\alpha \beta}^{(3)}, \quad s_{\alpha \beta}^{(3) *}=2{s^{\prime}}_{\alpha \beta}^{(3)}, \quad \sigma^{(3) *}=2{\sigma^{\prime}}^{(3)}, \\
& \varepsilon_{\alpha \beta}^{(3) *}=2 \varepsilon_{\alpha \beta}^{\prime(3)}, \quad \varepsilon_{\alpha \beta}^{(3) *}=2{\varepsilon^{\prime}}_{\alpha \beta}^{(k)}, \quad \varepsilon^{(3) *}=2 \varepsilon^{\prime(3)} .
\end{aligned}
$$

Repeating the procedure of derivation of equations of equilibrium for values with asterisks, will come to the same nonlinear system of differential equations. In the iterative form of this system will be similar to the system (6):

$$
\begin{aligned}
& a_{1} u_{1}^{* n}-a_{1} u_{2}^{* n}-a_{4} u_{1}^{* n}{ }_{x x}-a_{5} u_{2}^{* n},_{x x}+a_{2} w_{1}^{* n},_{x}+a_{3} w_{2}^{* n},_{x}-2 a_{6} w_{1}^{* n},_{x x x}+a_{7} w_{2}^{* n},_{x x x}=p_{\omega}^{*(n-1)} \text {, } \\
& -a_{1} u *_{1}^{n}+a_{1} u_{2}^{* n}-a_{5} u_{1}^{* n}{ }_{, x x}-a_{9} u_{2}^{* n}{ }_{x x}-a_{10} w_{1}^{* n}{ }_{, x}-a_{17} w *_{2}^{n}{ }_{, x}-a_{6} w_{1}^{* n}{ }_{x x x}+2 a_{7} w_{2}^{* n}{ }_{x x x}=h_{\omega}^{*(n-1)}, \\
& -a_{2} u_{1}^{* n}{ }_{x}+a_{10} u_{2}^{* n}{ }_{x}+2 a_{6} u_{1}^{* n}{ }_{x x x}+a_{6} u_{2}^{* n}{ }_{x x x}+a_{11} w_{1}^{* n}{ }_{x x}-a_{12} w_{2}^{* n}{ }_{x x}+ \\
& +a_{15} w_{1}^{* n},_{x x x x}-a_{16} w_{2}^{* n},_{x x x x}+a_{8} w_{1}^{* n}-a_{8} w_{2}^{* n}=q+q_{\omega}^{*(n-1)}, \\
& -a_{3} u_{1}^{* n},_{x}+a_{17} u_{2}^{* n},_{x}-a_{7} u_{1}^{* n},_{x x x}-2 a_{7} u_{2}^{* n}{ }_{x x x}-a_{12} w_{1}^{* n},_{x x}+a_{14} w_{2}^{* n}{ }_{x x}- \\
& -a_{16} w_{1}^{* n}{ }_{x x x x}+a_{13} w_{2}^{* n}{ }_{x x x x}-a_{8} w_{1}^{* n}+a_{8} w_{2}^{* n}=g_{\omega}^{*(n-1)} .
\end{aligned}
$$

Here, $n$ is the approximation number; the coefficients $a_{1}, \ldots, a_{19}$ are determined by formulas (6) at the temperature of unloading. In the additional loads $p_{\omega}^{*(n-1)}, h_{\omega}^{*(n-1)}$, $q_{\omega}^{*(n-1)}$, and $g_{\omega}^{*(n-1)}$, at the first step of approximation, the nonlinear terms are assumed equal to zero. Further, they are calculated from the results of the previous iteration by formulas (7), in which the corresponding quantities with asterisks, $H_{1}^{\omega(n-1) *}, H_{2}^{\omega(n-1) *}$, 
$P_{1}^{\omega(n-1) *}, P_{2}^{\omega(n-1) *}, T_{1}^{\omega(n-1) *}, T_{2}^{\omega(n-1) *}, S_{1}^{\omega(n-1) *}$, and $S_{2}^{\omega(n-1) *}$, are found from formulas (11), with addition of the superscript $\left(n^{\triangleleft} 1\right)^{*}$.

If the kinematic conditions of supporting of the beam at its end faces on spatially motionless rigid supports are assumed, then, at the sections $x=0, l$, the following requirements have to be obeyed at each step for the displacements marked with asterisks:

$$
w_{k}^{* n}=u_{k}^{* n},_{x}=w_{k}^{* n},_{x x}=0 \quad(k=1,2) .
$$

The solution of the system of differential equations (17) is assumed in the form of trigonometric series, automatically satisfying boundary conditions (18):

$$
\begin{aligned}
& u_{1}^{n *}=\sum_{m=1}^{\infty} U_{1 m}^{n *} \cos \left(\frac{\pi m x}{l}\right), \quad u_{2}^{n *}=\sum_{m=1}^{\infty} U_{2 m}^{n *} \cos \left(\frac{\pi m x}{l}\right), \\
& w_{1}^{n *}=\sum_{m=1}^{\infty} W_{1 m}^{n *} \sin \left(\frac{\pi m x}{l}\right), \quad w_{2}^{n *}=\sum_{m=1}^{\infty} W_{2 m}^{n *} \sin \left(\frac{\pi m x}{l}\right),
\end{aligned}
$$

where $U_{1 m}^{n *}, U_{2 m}^{n *}, W_{1 m}^{n *}$, and $W_{2 m}^{n *}$ are the displacements amplitudes required.

The external loads and additional forces marked by asterisks are also presented as trigonometric series:

$$
\begin{array}{cc}
q^{*}=\sum_{m=1}^{\infty} q_{m}^{*} \sin \left(\frac{\pi m x}{l}\right), \quad q_{m}^{*}=\frac{2}{l} \int_{0}^{l} q^{*}(x) \sin \left(\frac{\pi m x}{l}\right) \mathrm{d} x, \\
q_{\omega}^{(n-1) *}=\sum_{m=1}^{\infty} q_{\omega m}^{(n-1) *} \sin \left(\frac{\pi m x}{l}\right), \quad q_{\omega m}^{(n-1) *}=\frac{2}{l} \int_{0}^{l} q_{\omega}^{(n-1) *}(x) \sin \left(\frac{\pi m x}{l}\right) \mathrm{d} x, \\
g_{\omega}^{(n-1) *}=\sum_{m=1}^{\infty} g_{\omega m}^{(n-1) *} \sin \left(\frac{\pi m x}{l}\right), \quad g_{\omega m}^{(n-1) *}=\frac{2}{l} \int_{0}^{l} g_{\omega}^{(n-1) *}(x) \sin \left(\frac{\pi m x}{l}\right) \mathrm{d} x, \\
h_{\omega}^{(n-1) *}=\sum_{m=1}^{\infty} h_{\omega m}^{(n-1) *} \cos \left(\frac{\pi m x}{l}\right), \quad h_{\omega m}^{(n-1) *}=\frac{2}{l} \int_{0}^{l} h_{\omega}^{(n-1) *}(x) \cos \left(\frac{\pi m x}{l}\right) \mathrm{d} x, \\
p_{\omega}^{(n-1) *}=\sum_{m=1}^{\infty} p_{\omega m}^{(n-1) *} \cos \left(\frac{\pi m x}{l}\right), & p_{\omega m}^{(n-1) *}=\frac{2}{l} \int_{0}^{l} p_{\omega}^{(n-1) *}(x) \cos \left(\frac{\pi m x}{l}\right) \mathrm{d} x .
\end{array}
$$

Inserting displacements (19) and forces (20) into (17), we obtain a system of linear algebraic equations for determin-ing the displacement amplitudes $U_{1 m}^{n}, U_{2 m}^{* n}, W_{1 m}^{* n}$, and $W_{2 m}^{* n}$, which does not differ in its form from system (11) if asterisks are added to superscripts in the latter one.

After solving the system obtained, the displacements required, marked by asterisks, are calculated. The corresponding solution of the problem on deformation of the beam during the second half-cycle are found from relations (15) with account of solution (19):

$$
u_{k}^{\prime \prime}(x, z)=u_{k}^{\prime}(x, z)-u_{k}^{*}(x, z), \quad w_{k}^{\prime \prime}(x, z)=w_{k}^{\prime}(x, z)-w_{k}^{*}(x, z) \quad(k=1,2) .
$$


Here, the quantities with one prime are the stresses, strains, and displacements in the beam before unloading, calculated by formulas (9), with primes added to superscripts in its.

Numerical results. The numerical realization of solution (21), (15)-(19) was carried out for a three-layer D16T-fluoroplastic-D16T beam, whose mechanical and thermoplastical parameters are described in [2]. The temperature field in the filler was calculated by formula (1), at $h_{1}=0, q_{t}=5000 \mathrm{~J} /\left(\mathrm{m}^{2} \cdot \mathrm{s}\right)$ at the instant of time $t=60 \mathrm{~min}$. The rated temperature on beam surface was $540 \mathrm{~K}$. The intensity of load $q_{0}={ }^{\smile} 5 \mathrm{MPa}$.

On Figs. 4 deflections of the first layer in the cross section $x=0.5$ of the beam are shown in relation to the coordinates of endpoints of the interval of the locally distributed load. We should note that, at repeated sign-variable loading by uniformly distributed or local rectangular loads, the yield point of the material of load-carrying layers changed only due to hardening of the material, because temperature after the change in load sign did not change. Therefore, the maximum deflections in repeated loadings in the temperature field decreased by $1-2 \%$; however, in the case of subsequent cyclic changes in the load, this difference will accumulate.
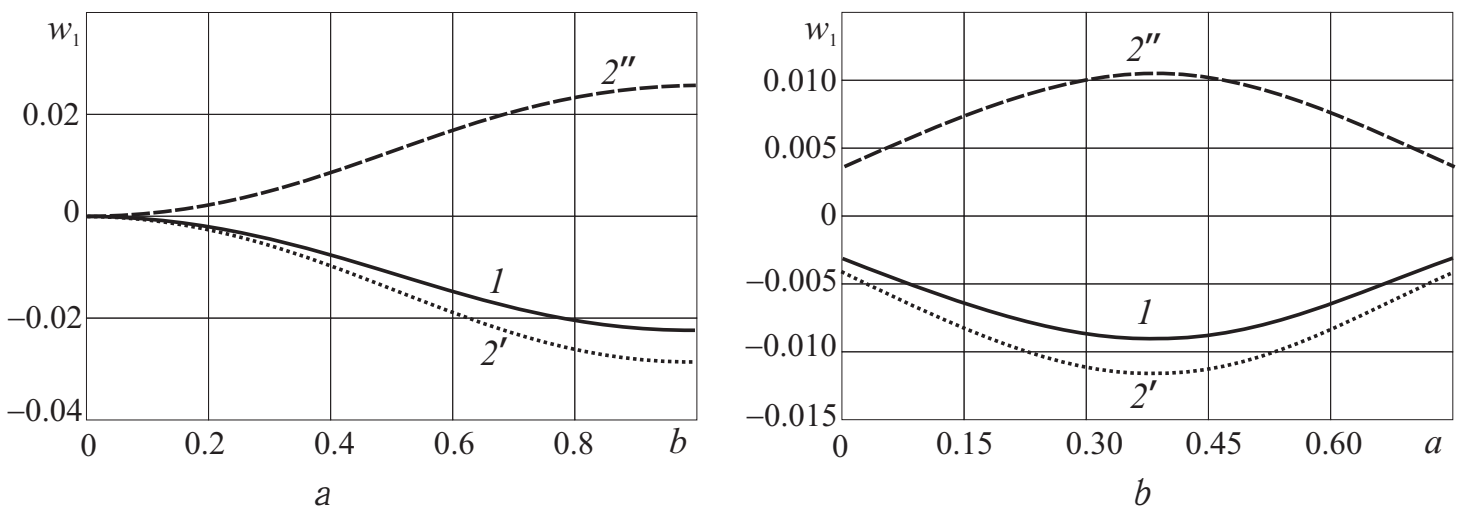

Fig. 4. Deflection $w_{1}$ in the middle of beams vs. coordinates $b(a)$ and $a(b)$ of ends of the interval of locally distributed load: elastic (1), thermoelastoplastic in loading from the natural state $\left(2^{\prime}\right)$, and thermoplastic in repeated sign-variable loading $\left(2^{\prime \prime}\right)$

\section{CONCLUSION}

The technique suggested for investigating a variable deformation of three-layer beams with a compressible filler allows one to take into account the effect of thermal flows and the physical nonlinearity of layer materials in engineering calculations. Numerical calculations have shown that their effect on the stresses and displacements in such a beam is considerable.

Acknowledgements: This work was supported by the Moscow Aviation Institute and Russian Science Foundation (project no. 14-49-00091).

\section{References}

1. Bolotin V. V., Novichkov Iu. N. Mekhanika mnogosloinykh konstruktsii [Mechanics of Multilayer Structures]. Moscow, Mashinostroenie, 1980. 375 p. (in Russian).

2. Gorshkov A. G., Starovoitov E. I., Tarlakovskii D. V. Teoriia uprugosti i plastichnosti [Foundations of the Theory of Elasticity and Plasticity]. Moscow, FIZMATLIT, 2011. 416 p. (in Russian). 
3. Tarlakovskii D. V., Fedotenkov G. V. Two-Dimensional Nonstationary Contact of Elastic Cylindrical or Spherical Shells. Journal of Machinery Manufacture and Reliability, 2014, vol. 43, no. 2, pp. 145-152. DOI: 10.3103/S1052618814010178.

4. Fedotenkov G. V., Tarlakovskiy D. V. Analytic Investigation of Features of Stresses in Plane Nonstationary Contact Problems With Moving Boundaries. J. Math. Sci., 2009, vol. 162, no. 2, pp. 246-253. DOI: 10.1007/s10958-009-9635-4.

5. Kuznetsova E. L., Tarlakovskii D. V., Fedotenkov G. V. Propagation of Unsteady Waves in an Elastic Layer. Mechanics of Solids, 2011, vol. 46, no. 5, pp. 779-787. DOI: 10.3103/S0025654411050128.

6. Mochalin A. A. Parametric Oscillations of a Non-uniform Circular Cylindrical Shell of Variable Density under Different Boundary Conditions. Izv. Saratov Univ. (N. S.), Ser. Math. Mech. Inform., 2015, vol. 15, iss. 2, pp. 210-214 (in Russian). DOI: 10.18500/18169791-2015-15-2-210-215.

7. Starovoitov E. I., Kubenko V. D., Tarlakovskii D. V. Vibrations of circular sandwich plates connected with an elastic foundation. Russian Aeronautics, 2009, vol. 52, no. 2, pp. 151157. DOI: $10.3103 /$ S1068799809020044.

8. Rabboh S. A., Bondok N. E., Mahmoud T. S., El Kholy H. I. The Effect of Functionally Graded Materials into the Sandwich Beam Dynamic Performance. Materials Sciences and Applications, 2013, vol. 4, pp. 751-760. DOI: 10.4236/msa.2013.411095.

9. Havaldar S., Sharma R. Experimental Investigation of Dynamic Characteristics of Multilayer PU Foam Sandwich Panels. Journal of Minerals and Materials Characterization and Engineering, 2013, vol. 1, no. 5, pp. 201-206. DOI: 10.4236/jmmce.2013.15031.

10. Leonenko D. V., Starovoitov E. I. Impulsive Action on the Three-Layered Circular Cylindrical Shells in Elastic Media. Izv. Saratov Univ. (N. S.), Ser. Math. Mech. Inform., 2015, vol. 15, iss. 1, pp. 202-209 (in Russian). DOI: 10.18500/1816-9791-2015-15-2-202209.

11. Blinkov Yu. A., Mesyanzhin A. V., Mogilevich L. I. Wave Occurrences Mathematical Modeling in Two Geometrically Nonlinear Elastic Coaxial Cylindrical Shells, Containing Viscous Incompressible Liquid. Izv. Saratov Univ. (N. S.), Ser. Math. Mech. Inform., 2016, vol. 16, iss. 2, pp. 184-197 (in Russian). DOI: 10.18500/1816-9791-2016-16-2-184-197.

12. Yang L., Harrysson O., West H., Cormier D. A. Comparison of Bending Properties for Cellular Core Sandwich Panels. Materials Sciences and Applications, 2013, vol. 4, no. 8, pp. 471-477. DOI: 10.4236/msa.2013.48057.

13. Belostochnyi G. N., Ul'yanova O. I. Continuum Model for a Composition of Shells of Revolution with Thermosensitive Thickness. Mechanics of Solids, 2011, vol. 46., no. 2, pp. 184-191. DOI: 10.3103/S0025654411020051.

14. Vaziri A., Xue Z., Hutchinson J. W. Metal sandwich plates with polymer foam-filled cores. Journal of Mechanics of Materials and Structures, 2006, vol. 1, no. 1, pp. 97-127. DOI: 10.2140/jomms.2006.1.97.

15. Leonenko D. V., Starovoitov E. I. Deformation of a three-layer elastoplastic beam on an elastic foundation. Mechanics of Solids, 2011, vol. 46, no. 2, pp. 291-298. DOI: 10.3103/S002565441102018X.

16. Starovoitov E. I., Leonenko D. V. Variable Bending of a Three-layer Rod with a Compressed Filler in the Neutron Flux. Izv. Saratov Univ. (N. S.), Ser. Math. Mech. Inform., 2017, vol. 17, iss. 2, pp. 196-208 (in Russian). DOI: 10.18500/1816-9791-2017-17-2-196-208. 
17. Franus D. V. Thickness Influence of the Multylayer Corneal Shell on the Value of Intraocular Pressure Izv. Saratov Univ. (N. S.), Ser. Math. Mech. Inform., 2017. vol. 17, iss. 2, pp. 183-195 (in Russian). DOI: 10.18500/1816-9791-2017-17-2-209-218.

18. Yankovskii A. P. A Study of Steady Creep of Layered Metal-composite Beams of Laminated- fibrous Structures with Account of Their Weakened Resistance to the Transverse Shift. Vestn. Samar. Gos. Tekhn. Univ. Ser. Fiz.-Mat. Nauki, 2016, vol. 20, no. 1, pp. 85-108 (in Russian). DOI: 10.14498/vsgtu1459.

19. Wilde M. V., Sergeeva N. V. Development of Asymptotic Methods for the Analysis of Dispersion Relations for a Viscoelastic Solid Cylinder. Izv. Saratov Univ. (N. S.), Ser. Math. Mech. Inform., 2017, vol. 17, iss. 2, pp. 183-195 (in Russian). DOI: 10.18500/18169791-2017-17-2-183-195.

20. Il'iushin A. A. Plastichnost'. Ch. 1. Uprugoplasticheskie deformatsii [Plastic. Ch. 1. Elastic-Plastic Deformation]. Moscow, Gostekhizdat, 1948. 376 p. (in Russian).

21. Moskvitin V. V. Tsiklicheskoe nagruzhenie elementov konstruktsii [Cyclic Loading of Elements of Designs]. Moscow, Nauka, 1981. 344 p. (in Russian).

\section{Cite this article as:}

Starovoitov E. I., Leonenko D. V. Bending of a Sandwich Beam by Local Loads in the Temperature Field. Izv. Saratov Univ. (N. S.), Ser. Math. Mech. Inform., 2018, vol. 18, iss. 1, pp. 69-83. DOI: 10.18500/1816-9791-2018-18-1-69-83.

УДК 539.374

\section{ИЗГИБ ТРЕХСЛОЙНОЙ БАЛКИ ЛОКАЛЬНЫМИ НАГРУЗКАМИ В ТЕМПЕРАТУРНОМ ПОЛЕ}

\section{Э. И. Старовойтов, Д. В. Леоненко}

Старовойтов Эдуард Иванович, доктор фризико-математических наук, заведующий кафедрой строительной механики Белорусского государственного университета транспорта, 246653, Беларусь, Гомель, Кирова, 34, edstar0@ yandex.by

Леоненко Денис Владимирович, доктор фризико-математических наук, просрессор касредры строительной механики Белорусского государственного университета транспорта, 246653, Беларусь, Гомель, Кирова, 34, leoden@tut.by

Рассмотрено десрормирование трехслойной балки в температурном поле под действием локальной распределенной нагрузки, сосредоточенной силы и момента. Аналитический вид нагрузок задавался с помощью фрункций Хевисайда. Для описания кинематики несимметричного по толщине трехслойного стержня приняты гипотезы ломаной линии: в тонких несущих слоях справедливы гипотезы Бернулли; в сжимаемом по толщине заполнителе выполняется гипотеза Тимошенко с линейной аппроксимацией перемещений по толщине слоя. Учитывается работа заполнителя в тангенциальном направлении. На границе предполагаются кинематические условия свободного опирания торцов стержня на неподвижные в пространстве жесткие опоры. Изменение температуры рассчитывалось с помощью фрормулы, полученной при осреднении теплосризических свойств материалов слоев по толщине стержня. Напряжения и десрормации связаны соотношениями десрормационной теории пластичности. Система дисрфреренциальных уравнений равновесия получена вариационным методом. Решение краевой за- 
дачи термо-, упругопластичности сведено к нахождению четырех искомых срункций: прогибов и продольных перемещений срединных поверхностей несущих слоев. Аналитическое решение получено методом упругих решений. Проведен его численный анализ в случае непрерывных, локально распределенных, сосредоточенных и циклических нагрузок. Приведены грасрики изменения напряжений и перемещений в трехслойной балке при изотермических и термосиловых нагрузках.

Ключевые слова: циклические локальные нагрузки, трехслойная упругопластичная балка, сжимаемый заполнитель, температурное поле.

Благодарности. Работа выполнена при поддержке Московского авиационного института и Российского научного фонда (проект № 14-49-00091).

\section{Образец для цитирования:}

Старовойтов Э. И., Леоненко Д. В. Bending of a Sandwich Beam by Local Loads in the Temperature Field [Изгиб трехслойной балки локальными нагрузками в температурном поле] // Изв. Сарат. ун-та. Нов. сер. Сер. Математика. Механика. Информатика. 2018. Т. 18, вып. 1. С. 69-83. DOI: 10.18500/1816-9791-2018-18-1-69-83. 